\title{
Mining downy mildew susceptibility genes: a diversity study in grapevine.
}

\section{Carlotta Pirrello ${ }^{1,2 *}$, Tieme Zeilmaker ${ }^{3}$, Luca Bianco', Lisa Giacomelli' ${ }^{1,3}$, Claudio Moser ${ }^{1}$, Silvia Vezzulli ${ }^{1}$}

${ }^{1}$ Research and Innovation Centre, Edmund Mach Foundation, Via E. Mach 1, 38010 San Michele all'Adige, Italy

${ }^{2}$ Department of Agricultural, Food, Environmental and Animal Sciences, University of Udine, via delle Scienze 206, 33100 Udine, Italy

${ }^{3}$ SciENZA Biotechnologies B.V., Sciencepark 904, 1098 XH Amsterdam, The Netherlands

* corresponding author: carlotta.pirrello@guests.fmach.it

\section{Acknowledgments}

$\mathrm{CP}$ acknowledges funding from a FEM PhD fellowship at University of Udine, including a support from SciENZA Biotechnologies bv.

\section{Conflict of Interest Statement}

The authors declare no conflict of interest. 


\begin{abstract}
Several pathogens continuously threaten viticulture worldwide. Until now, the investigation on resistance loci has been the main trend to understand the interaction between grapevine and mildew causal agents. Dominantly inherited gene-based resistance has shown to be race-specific in some cases, to confer partial immunity and to be potentially overcome within a few years since its introgression. Recently, on the footprint of research conducted on Arabidopsis, the putative hortologues of genes associated with downy mildew susceptibility in this species, have been discovered also in the grapevine genome. In this work, we deep-resequenced four putative susceptibility genes in 190 highly genetically diverse grapevine genotypes to discover new sources of broad-spectrum recessively inherited resistance. The scouted genes are VvDMR6-1, VvDMR6-2, $V v D L O 1, V v D L O 2$ and predicted to be involved in susceptibility to downy mildew. From all identified mutations, 56\% were Single Nucleotide Polymorphisms (SNPs) in heterozygosity, while the remaining $44 \%$ were homozygous. Regarding the identified mutations with putative impact on gene function, we observed $\sim 4 \%$ genotypes mutated in $V v D M R 6-1$ and $\sim 8 \%$ mutated in $V v D M R 6-2$, only a handful of genotypes that were mutated in both genes. $\sim 2 \%$ and $\sim 7 \%$ genotypes showed mutations in $V v D L O 1$ and $V v D L O 2$ respectively, and again a few genotypes resulted mutated in both genes. In particular, $80 \%$ of impacting mutations were heterozygous while $20 \%$ were homozygous. The current results will inform grapevine genetics and corroborate genomic-assisted breeding programs for resistance to biotic stresses.
\end{abstract}

\title{
Keywords
}

Amplicon sequencing, disease resistance, DLO, DMR, SNP, Vitis spp.

\section{Significance statement}

A survey on the genetic diversity of downy mildew susceptibility genes in grapevine varieties and wild species reveals a potential valuable for genomic-assisted breeding as well as tailored gene editing to induce disease resistance. 


\section{INTRODUCTION}

Crop plants encounter constant biotic challenges, and these threats have been commonly managed with pesticides and fungicides. Developing disease-resistant varieties is a convenient alternative to chemical control methods to protect crops from diseases. When a pathogen recognizes and invades the plant tissues and a plant-pathogen interaction is established, it faces the response of the host involving activation of signals that result in a rapid defence response. This immune response helps the host plant to avoid further infection of the disease (Gururani et al., 2012). To suppress this immunity, pathogens produce effector molecules to alter host responses and support compatibility. In turn, plants evolved the ability to recognize these effectors by using resistance (R) genes. The majority of R-genes encode nucleotide-binding leucine-rich-repeat (NBS-LRR) proteins. Since R genes are specifically directed towards highly polymorphic effector molecules or their modifications, this kind of immunity is dominantly inherited, mostly race-specific and rapidly overcome by the capacity of the pathogen to mutate (Jones \& Dangl, 2006). Analyses of whole-genome sequences have provided and will continue to provide new insights into the dynamics of R-gene evolution (Meyers, Kaushik, \& Nandety, 2005).

Besides the established $R$ gene model, the susceptibility $(S)$ gene model has been more recently defined. All plant genes that facilitate infection and support compatibility can be considered $S$ genes (reviewed in van Schie \& Takken, 2014). They can be classified into the following three groups based on the point at which they act during infection: those involved in early pathogen establishment, those involved in modulation of host defences, and those involved in pathogen sustenance (Fawke, Doumane, \& Schornack, 2015). The concept of susceptibility genes was first explored in barley by Jorgensen (1992) with the $M L O$ (Mildew resistance Locus O) gene involved in susceptibility to powdery mildew. Later, mlo mutants were identified also in cucumber, melon, pea, tomato and tobacco (Kusch \& Panstruga, 2017). Other analyzed susceptibility genes are the so called DMR (Downy Mildew Resistant) genes firstly characterized in Arabidopsis by Van Damme et al. (2005, 2008) and DLO (DMR-like Oxygenases) (K. Zhang, Halitschke, Yin, Liu, \& Gan, 2013). Initially the Arabidopsis thaliana dmr6 mutant was isolated from an EMS population for its resistance to Hyaloperonospora arabidopsidis, the DM causal agent in this species (Van Damme et al., 2005). Orthologs were readily identified in tomato (de Toledo Thomazella et al., 2016) as well as many other crops (e.g. Schouten, Krauskopf, Visser, \& Bai, 2014; Sun et al., 2017) and fruit trees (e.g. Zeilmaker et al., 2015; Zhang et al., 2018). Mutations in DMR6 confer broad-spectrum resistance; Sldmr6-1 tomato mutant plants show resistance against Phytophthora capsici; Pseudomonas siringae and Xanthomonas spp. (de Toledo Thomazella et al., 2016). 
In order to identify mutations and to deepen their impact on plant performance, studies of genetic diversity are essential and have been extensively performed in the plant kingdom, although compared to animals and humans their sequel is still in its infancy. A SNP (Single Nucleotide Polymorphism) provides the ultimate form of molecular marker, based on differences of individual nucleotide bases between DNA sequences (Ganal, Altmann, \& Röder, 2009). SNPs are more abundant in the genome and more stably inherited than other genetic markers (Brookes, 1999) and they can be classified into random, gene targeted, or functional markers according to their localization (Andersen \& Lübberstedt, 2003). The discovery of functional SNPs - that cause phenotype variations - is challenging and have been scarcely described in literature. In particular, functional SNPs were used to target flowering time and seed size in lentil (Polanco et al., 2019), midrib colour in sorghum (Burow et al., 2019), leaf hair number in turnip (Zhang et al., 2018), grain length (Fan et al., 2009) and blast resistance in rice (Yang et al., 2017).

A variety of approaches have been adopted to identify novel SNPs (Edwards et al., 2007). In the last decade, computational approaches have dominated SNP discovery methods due to the advent of Next Generation Sequencing (NGS, Varshney et al., 2009), followed by the third-generation sequencing platforms (TGS, Schadt, Turner and Kasarskis, 2010), and the consequent ever-increasing sequence information in public databases. Since the first whole plant genome sequenced (The Arabidopsis Genome Initiative, 2000), de novo and reference-based SNP discovery and application are now feasible for numerous plant species. Large scale SNP discovery was performed in almost all sequenced plant genomes such as maize (Ching et al., 2002), Arabidopsis (Atwell et al., 2010), rice (Xu et al., 2012), rapeseed (Raman et al., 2014), potato (Vos et al., 2015), and pepper (Hulse-Kemp et al., 2016). On the method side, Genotyping-By-Sequencing (GBS) has recently emerged as a promising genomic approach to explore plant genetic diversity on a genome-wide scale (Peterson $e t$ al., 2014), followed by the more cost-effective Genotyping-in-Thousands by sequencing (GT-seq) (Campbell, Harmon, \& Narum, 2015). Genetic applications such as linkage mapping, phylogenetics, population structure, association studies, map-based cloning, marker-assisted plant breeding, and functional genomics continue to be enabled by access to large collections of SNPs (Kumar, Banks, \& Cloutier, 2012). In parallel to SNP discovery based on whole genome sequencing, amplicon sequencing has also been successfully applied in plants (e.g. Durstewitz et al., 2010; Yang et al., 2016; Cho, Jones and Vodkin, 2017; Shimray et al., 2017) although less frequently than in bacteria (e.g. Hong et al., 2015) or viruses (e.g. Kinoti et al., 2017).

Recently, as advocated by Gupta et al. (2001), progress has also been made in the development and use of SNPs in woody plants, including some crop and tree species as apple (Bianco et al., 2016), walnut (Marrano et al., 2019), sweet cherry (Hardner et al., 2019), pear (X. Li et al., 2019), and coffee 
(Merot-L'anthoene et al., 2019). This phenomenon is due to the boost in the sequencing of cultivated plant genomes to provide high-density molecular markers for breeding programs aimed to crop improvement as well as to clear up evolutionary mechanisms through comparative genomics (Feuillet et al., 2011; Bolger et al., 2014). In grapevine a great deal of progress has been made from the first SNP identification in the pre-genomic-era (Owens, 2003) to the sequencing of the whole genome of several Vitis vinifera cultivars (Jaillon, 2007; Velasco et al., 2007; Carrier et al., 2012; Gambino et al., 2017; Roach et al., 2018) and to the very recent report of the genome sequence of Vitis riparia (Girollet, Rubio, \& Bert, 2019).The latter represents a turning point on the scavenging of genomes that are donors of disease resistance. This issue in Vitis spp. is faced by identifying $R$ loci, underlying $R$ genes, through Quantitative Trait Loci (QTL) analysis in different genetic backgrounds. Nowadays, $13 R$ loci against powdery mildew and 27 to downy mildew have been identified with different origins; mainly from American and Asian wild species (Topfer and Hausmann , 2010).

Nowadays, a promising approach to cope with disease resistance is represented by the study of $S$ loci. Based on a high-resolution map, Barba et al., (2014) identified on chromosome 9 a locus (Sen1) for powdery mildew susceptibility from 'Chardonnay', finding evidence for quantitative variation. Moreover, on the footprint of research conducted on model plants, genes associated with mildew susceptibility have been discovered and dissected also in the grapevine genome. $7 \mathrm{VvMLO}$ orthologs in tomato and Arabidopsis were identified and members of $V v M L O$ gene family showed transcriptional induction upon fungal inoculation (Winterhagen et al., 2008; Feechan, Jermakow and Dry, 2009). Lately, a significant response in terms of powdery mildew resistance has been achieved by silencing of $V v M L O 7$ and $V v M L O 6$ through RNAi in grapevine (Pessina et al., 2016).

In this research we aim to investigate the diversity of the DMR6 and DLO genes in a wide set of Vitis spp. to broaden our knowledge of the genetic variation present. This information will enhance our knowledge of possible alternative or integrative solutions compared to the use of $R$ loci.

\section{RESULTS AND DISCUSSION}

\section{Sequencing and mapping}

In order to identify potentially disrupting mutations, coding sequences of the four $V v D M R 6.1$, VvDMR6.2, $V v D L O 1$ and $V v D L O 2$ genes (Table 1) from 190 genotypes (Table S1) were deepsequenced and mapped on the reference genome PN40024 12X V2 (see Materials and Methods section). Total sequence coverage of all genes together was 12,476,502 reads. VvDMR6.1 was covered by $5,450,614$ reads (44\%), VvDMR6.2 by 3,476,587 (28\%), VvDLO1 by 3,270,318 (26\%), and $V v D L O 2$ by 278,983 (2\%). The highest coverage was detected in hybrid genotypes with a total 
of 9,357,649 reads (75\%), followed by vinifera with 1,333,887 (11\%), hybrids/wild species with 964,847 (8\%) and wild species with 814,225 (6\%).

A total of 738 mutations were detected; $17(\sim 2 \%)$ short In/Dels and 721 point mutations, including heterozygous (56\%) and homozygous (44\%) SNPs.

\section{Genetic diversity assessment}

Amplicons were classified according to their rate of polymorphism: from the most polymorphic VvDLO2_1 ( $13 \%$ of the total mutations); to the ones carrying $\sim 8 \%$ of mutations VvDMR6.1_3, VvDMR6.1_2, VvDMR6.2_3 gradually decreasing to the lowest rate of polymorphism (less than 3\%) in VvDMR6.2_7 and VvDLO1_4.

Moreover, out of a total 738 mutations, $25(\sim 3.4 \%)$ triallelic variants were detected of which 13 in hybrids, 8 in wild species, 9 in vinifera varieties and 8 in hybrid/wild species. Triallelic mutations were mainly found in $V v D L O 2(12 ; \sim 1.6 \%)$ followed by $V v D M R 6.1$ (7; 1\%), VvDMR6.2 $3(\sim 0.4 \%)$ and $V v D L O 1$. As reported by Bianco et al. (2016) and Marrano et al. (2019), triallelic variants are usually discarded in SNP-based analyses to avoid incorrect genotypic information. Nevertheless, other authors provide data on their abundancy. The occurrence of the identified triallelism for each gene is consistent with previous work in grapevine (Lijavetzky et al., 2007; Vezzulli et al., 2008a; 2008b). In contrast, such a high representation of triallelic mutations in our accessions is due to the great genetic variability considered.

Considering the 696 biallelic mutations in all genotypes, $75 \%$ were transitions ( $A \leftrightarrow G, C \leftrightarrow T)$ and $25 \%$ were transversions $(A \leftrightarrow C, A \leftrightarrow T, C \leftrightarrow G, G \leftrightarrow T$ ) with a transition/transversion ratio of 3 . Both vinifera varieties and hybrids show the same assortment with $77 \%$ transitions and $23 \%$ transversions, quite far from the ratio $(\sim 1.6)$ observed in the same taxa by Vezzulli et al. (2008a). In wild species the percentages were $73 \%$ and $27 \%$ respectively, while $71 \%$ and $29 \%$ were the values observed in hybrid/wild species genotypes. The current results slightly diverge from the usual transitions/transversions ratio found in grapevine ( 1.5 in Salmaso et al., 2004; Lijavetzky et al., 2007; Vezzulli et al., 2008a; 2008b; 2 in Marrano et al., 2017) as well as in beetroot (Schneider et al., 2001), potato (Simko, Haynes, \& Jones, 2006) and cotton (Byers et al., 2012), while they are much higher than in soybean (Zhu et al., 2003) and almond (Wu et al., 2008).

SNP frequency was calculated as average and per gene for every taxon. Vinifera varieties showed the lowest average frequency ( 1 variant every $68.25 \mathrm{bp}$ ) with high differences between the target genes: 1 every 30.36 bp in VvDMR6.1, 1 every 46.09 bp in VvDMR6.2, 1 every 56.32 bp in $V v D L O 1$ and 1 every $140.22 \mathrm{bp}$ in $V v D L O 2$. A comparable polymorphism rate (1 SNP every $69 \mathrm{bp}$ in coding regions) was found in both cultivated (spp. sativa) and non-cultivated (spp. sylvestris) 
Table 1. Targeted genes, amplicons with their genome positions and primers.

\begin{tabular}{|c|c|c|c|c|c|}
\hline Gene & ID & Amplicon & Illumina forward primer & Illumina reverse primer & Amplicon Position \\
\hline \multirow[t]{6}{*}{ VvDMR6.1 } & \multirow[t]{6}{*}{ VIT_216s0098g00860 } & 1 & 5'- CTGCTTAGTAGAGTGGTTAT -3' & 3'- CGATGTGTTGGATGAGTTGG -5' & Intron-Exon 1 Junction \\
\hline & & 2 & 5'- ATGTCCCCATAATCGACCTC -3' & 3'- GTAGAACTCATCGGCCACCT -5' & Exon 1- Intron Junction \\
\hline & & 3 & 5'- ATGGGGTAGCTGCAGAAATG -3' & 3'- TTGAAGGAAGGAGGATTGGA -5' & Exon 2 \\
\hline & & 4 & 5'- TCTCGAACAAATCCTAATTCAAAA -3' & 3'- GAAGAATGGTAAGGGCGTTG -5' & Intron-Exon 3 Junction \\
\hline & & 5 & 5'- AACCCGAGCTCACTTATGGA -3' & 3'- AAATTTTAAAAACCGGGCAAA -5' & Exon 3-Intron Junction \\
\hline & & 6 & 5'- GGAAATGGGCATGTGCTAATA -3' & 3'- TGCCCCAGAACTTCTTGTAA -5' & Intron-Exon 4 Junction \\
\hline \multirow[t]{7}{*}{ VvDMR6.2 } & \multirow[t]{7}{*}{ VIT_213s0047g00210 } & 1 & 5'- TCGGAGTCTTCACTCCCTTT -3' & 3'- GCCATAACGGCTACAAGCAT -5' & Exon 1 \\
\hline & & 2 & 5'- GGTGTGGATGTGACCAGTGA -3' & 3'- CCAAAGGATGGCAATGAAGT -5' & Intron-Exon 2 Junction \\
\hline & & 3 & 5'- AGGAGAAAGTGCACAATTGGA -3' & 3'- TCCGAAAAGGAAAAATGATGC -5' & Exon 2-Intron Junction \\
\hline & & 4 & 5'- TCCAAAATGAAGACATAAGAAGGA -3' & 3'- TATGTGCTGGCAGTCCGTAA -5' & Intron-Exon 3 Junction \\
\hline & & 5 & 5'- CTTGTCCCGAGCCAGAGTTA -3' & 3'- CCTGCATGCAATCATTTGTT -5' & Exon 3-Intron Junction \\
\hline & & 6 & 5'- CCCAGGTGCTTTTGTTGTTA -3' & 3'- CCCTTGCTGGACTAATGAGC -5' & Exon 3- Exon 4 Junction \\
\hline & & 7 & 5'- CGATTGCTTCTTTCCTCTGC -3' & 3'- CGCATTATGCCTTGTTGAAG -5' & Exon 4 \\
\hline \multirow[t]{5}{*}{ VvDLOI } & \multirow[t]{5}{*}{ VIT_215s0048g02430 } & 1 & 5'- ACAGGCCATCCCTCAGTACA -3' & 3'- ATCGACATGTACCCGAAAAA -5' & Exon 1 \\
\hline & & 2 & 5'- CCTTGCTTTGACATGATTCTTC -3' & 3'- TGAAAGATGGAGGGTTGGAG -5' & Exon 2 \\
\hline & & 3 & 5'- CCAACTGGAGAGATTTCCTGA-3' & 3'- CGCCTTATCTATGTGGTTCCTC -5' & Exon 2- Exon 3 Junction \\
\hline & & 4 & 5'- CTGGCCATGCTGATCCTAAT -3' & 3'- CCTATGGACCGCACTCTTGT -5' & Exon 3- Exon 4 Junction \\
\hline & & 5 & 5'- TTCCTGTAAAGGGCAGGATG -3' & 3'- TTCCTGTAAAGGGCAGGATG -5' & Exon 3- Exon 4 Junction \\
\hline \multirow[t]{5}{*}{ VvDLO2 } & \multirow[t]{5}{*}{ VIT_202s0025g02970 } & 1 & 5'- CAACCCCCACTTGTGAATTT -3' & 3'- CTTGGCCAATCTGTTTGACA -5' & Intron-Exon 1 Junction \\
\hline & & 2 & 5'- AAGGATGTCCAGGCATCAGA -3' & 3'- GAGCCTGACTGGATTGGAAG -5' & Exon 1 \\
\hline & & 3 & 5'- AGCTGCCAGAAAGCGAGA -3' & 3'- CATGTAACTGCATGTTGGTCAG -5' & Exon 1-Intron Junction \\
\hline & & 4 & 5'- TCTGACCAACATGCAGTTACA -3' & 3'- TCTTGGAGAAGAACTGTGATTAAA -5' & Intron-Exon 2 Junction \\
\hline & & 5 & 5'- CTTATGGGTTGCCTGGACAT -3' & 3'- TTTTCCTCATTTTTGCAGGTG -5' & Exon 2-Intron Junction \\
\hline
\end{tabular}


vinifera species by Lijavetzky et al. (2007). In contrast, Vezzulli et al. (2008a) estimated 1 SNP every 117 bp in cultivated vinifera and 1 every 169 bp in wild vinifera individuals coding sequence.

Moreover, in this study the detected average frequency was 1 variant every 55 bp in both wild species and hybrid/wild species genotypes, while for the single genes they showed respectively 1 every 43.17 bp and 1 every 25.43 bp in $V v D M R 6.1,1$ every 50.70 bp and 56.33 bp in $V v D M R 6.2,1$ every 77.63 bp and 94.09 bp in $V v D L O 1$ and 1 every 45.52 bp and 49.86 bp in VvDLO2. Hybrids showed a higher average frequency ( 1 every $36.44 \mathrm{bp}$ ) due to the dramatically high frequency values in $V v D M R 6.1$ (1 every $13.41 \mathrm{bp}$ ) and in $V v D M R 6.2$ (1 every $19.95 \mathrm{bp}), 1$ every 26.46 bp in $V v D L O 1$ and 1 every 85.92 bp in VvDLO2. Studying different Vitis spp. genotypes, Salmaso et al. (2004) observed an average of $1 \mathrm{SNP}$ every $47 \mathrm{bp}$ in the coding sequence of a set of genes encoding proteins related to sugar metabolism, cell signalling, anthocyanin metabolism and defence. Based on the first Pinot noir consensus genome sequence, the average SNP frequency was estimated at 4 SNPs every $\mathrm{Kb}$ (Velasco et al., 2007), compatible with the use of such molecular markers for the construction of genetic maps in grapevine (Salmaso et al., 2008). Higher polymorphism rates were found in other highly heterozygous tree species as peach (1 every 598 bp; Aranzana et al., 2012), black cottonwood (1 every 384bp; Tuskan et al., 2006), almond (1 every 114 bp; Wu et al., 2008) and Tasmanian blue gum tree (1 every 45 bp; Thavamanikumar et al., 2011).

As explained by Jones et al. (2007) and Grattapaglia et al. (2011), genotyping studies take advantage of different molecular markers, mostly relying on their informativeness. In this framework, SNPs are highly informative markers and this peculiarity is calculated as Minor Allele Frequency (MAF). SNPs are considered interesting for many goals when MAF values are >0.05 (Biswas et al., 2015; Cheng et al., 2019) but their main usefulness is due to the transferability across genotypes (>0.1; Lijavetzky et al., 2007). In the current study, MAF was calculated for each biallelic mutation. MAF values $0.01 \leq x \leq 0.05$ are represented by the $29 \%$ of mutations detected in total genotypes, in particular by the $23 \%, 0 \%, 2 \%$ and $3 \%$ in hybrids, wild species, vinifera varieties and hybrids/wild species, respectively. Values $0.05<\mathrm{x} \leq 0.1$ are represented by $3 \%$ of the mutations in total genotypes and in wild species and by $2 \%$ in hybrids, vinifera varieties and hybrid/wild species. $0.1<\mathrm{x} \leq 0.3 \mathrm{MAF}$ values are represented by the $5 \%$ of mutations in total genotypes as in hybrids; wild species and vinifera varieties represented them by the $4 \%$ of their mutations and hybrid/wild species by the $2 \%$. A very low percentage of mutations showed MAF $0.3<\mathrm{x} \leq 0.5: 3 \%$ for total genotypes, hybrids and vinifera; $2 \%$ for wild species and hybrid/wild species. Finally, MAF $>0.5$ was very poorly represented by mutations in total genotypes and each taxon. SNP informativeness depends on their reliability among individuals and species and their high transferability rates probably are not consistent with a direct impact on the genetic sequence (when in coding regions). Considering previous studies in 
grapevine, a larger representativeness of MAF values <0.1 was found in non-vinifera genotypes and rootstocks, non-cultivated vinifera showed a MAF $0.05<x<0.3$ while MAF $>0.1$ were severely represented by vinifera sativa (Lijavetzky et al., 2007; Vezzulli et al., 2008a; Emanuelli et al., 2013; Marrano et al., 2017). In the current study, the aim to focus on impacting mutations was achieved, since MAF $\leq 0.05$ is a distinguishing mark for rare SNPs, which may be not considered interesting for SNP-arrays but which are most likely affecting the gene sequence and putatively protein activity.

\section{Mutation impact evaluation}

In crops like tomato (Aflitos et al., 2014) and cucurbita spp. (Xanthopoulou et al., 2019), coding regions and whole genome sequence were scouted to find impacting mutations using SnpEff (Cingolani et al., 2012). A non-synonymous/synonymous mutation ratio of $\sim 1.5$ was found in tomato cultivated cv. In cucurbita spp., the ratio was $\sim 0.8$ but only $9 \%$ of genetic variants showed HIGH or MODERATE impact in full genomic sequence, suggesting a great presence of intergenic mutations. In walnut tree genomic sequence, Marrano et al. (2019) identified $2.8 \%$ potentially impacting variants, while in the pear genome $55 \%$ of mutations were classified as missense and $1 \%$ with $\mathrm{HIGH}$ impact (Dong et al., 2019).

In the current study, upon the variant discrimination performed according to their impact on codon sequence, $27 \%$ of total mutations (in particular, 27\% in VvDMR6.1, 25\% in VvDMR6.2, 30\% in $V v D L O 1$ and $25 \%$ in $V v D L O 2)$ were classified as "MODIFIER": falling into intronic regions or upstream/downstream the gene. "LOW" impact variants represented the 32\% (36\% in VvDMR6.1, $32 \%$ in $V v D M R 6.2,32 \%$ in $V v D L O 1$ and $28 \%$ in $V v D L O 2)$, responsible for synonymous mutations or falling into splice regions. Of total mutations, 38\% (in particular, 35\% in VvDMR6.1, 40\% in $V v D M R 6.2,35 \%$ in $V v D L O 1$ and $43 \%$ in $V v D L O 2)$ brought to non-synonymous variants and were then classified with "MODERATE" impact. Percentages partially corroborated in vinifera by Amrine et al. (2015), with $~ 90 \%$ of MODIFIER and LOW mutations and $~ 8 \%$ non-synonymous variants in gene sequence. The lowest number of variants (3\%: $2 \%$ in $V v D M R 6.1,2 \%$ in $V v D M R 6.2,3 \%$ in $V v D L O 1$ and $4 \%$ in $V v D L O 2$ ) was classified with "HIGH" impact as being responsible for sequence frameshift or premature stop codon occurrence. A significantly lower presence $(0.7 \%)$ of $\mathrm{HIGH}$ impacting variants was observed in Thompson Seedless cv. by Cardone et al. (2016). The current aim to detect potentially disrupting mutations finds support in the great frequency of HIGH- and MODERATE-impact variants compared to the aforementioned works on grapevine.

Following the filtering of mutations classified as "MODERATE" and "HIGH" (41\%) in order to discriminate amino acid variants according to their conservation, these variants were further checked and mutants carrying different chemical/physical properties from the reference were chosen 
(see Materials and Methods section). Finally, results from both analyses on amino acid sequence were cross-referenced and a total of 19 mutations was elected as potentially affecting the protein structure: 5 in VvDMR6.1, 4 in VvDMR6.2, 4 in VvDLO1 and 6 in VvDLO2 (Table S2).

Given the predicted complementarity of AtDMR6 and AtDLO in salicylic acid catabolism (K. Zhang et al., 2013; Y. J. Zhang et al., 2017), particular interest in these results is given by the occurrence of impacting elected mutations in each one of the four scouted genes. This may allow the use of VvDMR6 and $V v D L O$ genes in different combinations to enhance the impact of such homozygous mutations and likely avoid complementary effects.

\section{Mutated DMR and DLO gene combinations}

Of the studied genotypes, 55 showed at least one of the elected mutations: 37 hybrids, 2 vinifera varieties, 6 wild species and 10 hybrid/wild species. $73 \%$ of 55 genotypes showed mutations only in one gene: 13\% in $V v D M R 6.1,29 \%$ in $V v D M R 6.2,7 \%$ in $V v D L O 1$ and 24\% in $V v D L O 2$, while $27 \%$ were double mutants within 6 gene combinations (Table 2). Frequencies of occurring mutation arrangement (consensus sequence) were calculated for each gene. Regarding VvDMR6.1 one main mutations set was shared by $13 \%$ of genotypes (belonging to hybrid taxon). $46 \%$ and $19 \%$ of genotypes (both clusters with only hybrid individuals) showed two shared assortments for VvDMR6.2. Only one set in $V v D L O 1$ was shared by $15 \%$ of genotypes (all wild species) while three different $V v D L O 2$ sets were shared respectively by $13 \%$ (all hybrids), 13\% (belonging to hybrid and wild species taxon) and 9\% (hybrid and hybrid/wild species individuals) of genotypes. All other genotypes showed unique assortment of mutations.

Induction of plant defence signalling involves the recognition of specific pathogen effectors by the products of specialized host $R$ genes. Numerous plant $R$ genes have already been identified and characterized and they are being efficiently used in crop improvement research programs (Gururani et al., 2012). However, especially in tree species, selection of desirable resistant mutants come with a cost of lengthy and laborious breeding programs. The effort required to produce resistant plants is often baffled within a few years from the selection because the pathogen evolves mechanisms to circumvent the R-gene mediated immunity (Schaart et al., 2016; Bisht et al., 2019).

Exploitation of inactive alleles of susceptibility genes seems to be a promising path to introduce effective and durable disease resistance. Since S genes first discovery (Jorgensen, 1992), converting susceptibility genes in resistance factors has become the increasingly complementary strategy to that of breeding for R loci (van Schie \& Takken, 2014), and the advent of new reliable genome editing tools has enhanced this trend. The use of genome editing technologies such as CRISPR-Cas9 allow to specifically and rapidly target susceptibility genes to indirectly obtain 
resistance in a chosen genetic background, which is highly desired in crops like grapevine where the genetic identity is economically important. However, generation of edited plants and testing of their phenotype still requires years (ffrench-Constant \& Bass, 2017; Zaidi et al., 2018). S genes may play different functions in the plant, thus pleiotropic effects associated with their knock-out may entail a certain fitness cost for the plant. Recently, quantitative regulation of gene expression has been achieved with genome editing on cis-regulatory elements (Rodríguez-Leal et al., 2017; Wolter \& Puchta, 2018; Bisht et al., 2019) and this might be a strategy to limit negative drawbacks associated with a reduced S-gene function.

In this framework, thorough genetic diversity studies, as the one presented here, hold the potential to become a resource in different plant science contexts. The detection of specific homozygous variants in the natural pool can guide genome editing projects in targeting the "naturally" occurring mutations. This "tailored gene editing" mimicking natural polymorphisms, has been recently demonstrated by Bastet et al. (2017; 2019). Moreover, breeding programs could take advantage of the information on homozygous and heterozygous selected mutations of S-genes in a next-generation marker-assisted breeding program. 
bioRxiv preprint doi: https://doi.org/10.1101/2020.01.15.898700; this version posted January 15,2020 . The copyright holder for this preprint (which was not certified by peer review) is the author/funder, who has granted bioRxiv a license to display the preprint in perpetuity. It is made available under aCC-BY-NC-ND 4.0 International license.

Table 2. List of accessions carrying impacting mutations.

\begin{tabular}{|c|c|c|c|c|c|}
\hline Genotype & Taxon & VvDMR6.1 & VvDMR6.2 & VvDLO1 & VvDLO2 \\
\hline B87-60 & Vitis hybrid & & $\mathrm{He}$ & & \\
\hline Blanc du Bois & Vitis hybrid & $\mathrm{He}$ & & & \\
\hline Blue Lake & Vitis hybrid & $\mathrm{He}$ & $\mathrm{He}$ & & \\
\hline Captivator & Vitis hybrid & & $\mathrm{He}$ & & \\
\hline Catawba & Vitis hybrid & & $\mathrm{He}$ & & \\
\hline Chancellor & Vitis hybrid & $\mathrm{He}$ & & & $\mathrm{He}$ \\
\hline Clinton & Vitis hybrid & & Ho & & $\mathrm{He}$ \\
\hline D'Arpa & Vitis hybrid & & $\mathrm{He}$ & & \\
\hline Diamond & Vitis hybrid & & & & $\mathrm{He}$ \\
\hline F560 Big Brown & Vitis hybrid & & & $\mathrm{He}$ & \\
\hline FLA 449 & Vitis hybrid & & $\mathrm{He}$ & & \\
\hline FLA W1521 & Vitis hybrid & & Ho & & \\
\hline Golden Muscat & Vitis hybrid & & $\mathrm{He}$ & & $\mathrm{He}$ \\
\hline Herbert & Vitis hybrid & & $\mathrm{He}$ & $\mathrm{He}$ & \\
\hline Kunleany & Vitis hybrid & & & $\mathrm{He}$ & \\
\hline Lenoir & Vitis hybrid & & & Ho & \\
\hline M11-14/St. George & Vitis hybrid & & & & $\mathrm{He}$ \\
\hline Mantey & Vitis hybrid & & & Ho & \\
\hline Mars & Vitis hybrid & & $\mathrm{He}$ & & \\
\hline MW 66 & Vitis hybrid & $\mathrm{He}$ & & & \\
\hline NY08.0701b & Vitis hybrid & $\mathrm{He}$ & & & \\
\hline NY63.1016.01 & Vitis hybrid & $\mathrm{He}$ & & & \\
\hline NY65.0562.01 & Vitis hybrid & & & & $\mathrm{He}$ \\
\hline NY84.0100.05 & Vitis hybrid & $\mathrm{He}$ & & & \\
\hline NY97.0503.02 & Vitis hybrid & $\mathrm{He}$ & & & $\mathrm{He}$ \\
\hline NY97.0512.01 & Vitis hybrid & & $\mathrm{He}$ & & $\mathrm{He}$ \\
\hline Ontario & Vitis hybrid & & & & $\mathrm{He}$ \\
\hline Petra & Vitis hybrid & $\mathrm{He}$ & & $\mathrm{He}$ & \\
\hline Pixiola & Vitis hybrid & & & & $\mathrm{He}$ \\
\hline Schuyler & Vitis hybrid & & & & $\mathrm{He}$ \\
\hline Seibel 880 & Vitis hybrid & & & & $\mathrm{He}$ \\
\hline Sheridan & Vitis hybrid & & Ho & & \\
\hline Steuben & Vitis hybrid & & & & $\mathrm{He}$ \\
\hline$V$. riparia $x V$. cordifolia & Vitis hybrid & & & & $\mathrm{He}$ \\
\hline Venus & Vitis hybrid & $\mathrm{He}$ & $\mathrm{He}$ & & \\
\hline Wayne & Vitis hybrid & & $\mathrm{He}$ & & \\
\hline Worden & Vitis hybrid & & Но & & $\mathrm{He}$ \\
\hline V. aestivalis & Vitis spp. & & & & $\mathrm{He}$ \\
\hline V. berlandieri Texas & Vitis spp. & & & Ho & $\mathrm{He}$ \\
\hline V. cordifolia & Vitis spp. & & & $\mathrm{He}$ & $\mathrm{He}$ \\
\hline V. rubra & Vitis spp. & & $\mathrm{He}$ & & \\
\hline V. rupestris du Lot & Vitis spp. & $\mathrm{He}$ & & & \\
\hline
\end{tabular}




\begin{tabular}{|l|l|ll|} 
V. smalliana & Vitis spp. & & He \\
Coia1 & Vitis spp./hybrid & Ho & \\
Coia10 & Vitis spp./hybrid & Ho & \\
Coia11 & Vitis spp./hybrid & Ho & He \\
Coia12 & Vitis spp./hybrid & Ho & \\
Coia5 & Vitis spp./hybrid & Ho & He \\
Coia7 & Vitis spp./hybrid & Ho & \\
Coia9 & Vitis spp./hybrid & Ho & He \\
Corella2 & Vitis spp./hybrid & & Ho \\
Lorenzo1 & Vitis spp./hybrid & & He \\
Franconia & Vitis vinifera & & He \\
Italia & Vitis vinifera & & \\
Pinot gris & Vitis vinifera & Ho & \\
\hline
\end{tabular}




\section{MATERIALS AND METHODS}

\section{Genetic material and target genes}

In the current study, the four $V v D M R 6.1, V v D M R 6.2, V v D L O 1$ and $V v D L O 2$ genes were scouted in 190 grapevine genotypes (Table 1, Table S1). Out of these, 139 (73\%) are Vitis hybrids, $28(15 \%)$ are $V$. vinifera varieties, $12(6 \%)$ belong to wild Vitis species and additional $11(6 \%)$ are ascribed as hybrids/wild species.

\section{Amplicon sequencing and read processing}

Genomic DNA was extracted from young grapevine leaves using DNeasy Plant Mini Kit (QIAGEN, Hilden, Germany.) according to the manufacturer's protocol, then used to produce amplicons for deep-sequencing. PCR on the templates was performed using Phusion High-Fidelity Polymerase (NEB, Ipswich, Massachusetts, USA) according to the manufacturer's protocol. Primers were specifically designed to amplify $250 \mathrm{bp}$ of the coding regions of target genes and barcoded followed by in-house sequencing using the Illumina MiSeq platform (Table 1). A total of 19 amplicons was sequenced including six amplicons for $V v D M R 6.1$, seven amplicons for $V v D M R 6.2$, four amplicons for $V v D L O 1$ and two amplicons for $V v D L O 2$.

Obtained amplicons were then mapped on the PN40024 12X reference genome (Jaillon, 2007) considering the latest V2 gene prediction (Vitulo et al., 2014; Canaguier et al., 2017) through Burrows-Wheeler alignment (BWA; Heng Li \& Durbin, 2010) with no filter on mapping quality.

\section{Data mining}

Variant calling was performed by BCFtools (H. Li et al., 2009) using the following settings: minimum mapping quality 20; minimum genotype quality 20; minimum base quality 20; maximum per sample depth of coverage 1,000; minimum depth of coverage per site 10; keep read pairs with unexpected insert sizes (for amplicon sequencing). Filtering of results was done with VCFtools (Danecek et al., 2011) to exclude all genotypes with quality below 20 and include only genotypes with read depth $\geq 10$.

SnpEff was used to further discriminate variants according to their impact (MODIFIER, HIGH, MODERATE or LOW) on gene sequence (Cingolani et al., 2012). Elected-impacting variants were then subject to SIFT (Sorting Intolerant From Tolerant) (P. Kumar, Henikoff, \& Ng, 2009) analysis to assess the tolerance of aminoacidic variants on the protein primary structure, based on the alignment with sequences in SWISS-PROT/TrEMBL database. Only not tolerated mutations were considered for a last impact evaluation based on variants chemical-physical properties according to 
Betts \& Russell (2003) (Figure 1). Both SnpEff and SIFT algorithms were used with default parameters settings.

\section{Statistical analysis}

Data obtained from mapping and variant calling were dissected to extrapolate overall genetic information on the studied genotypes. Amplicons were classified according to their level of polymorphism. All the other parameters were calculated considering total accessions and the various taxon. For each gene, frequencies of occurring mutation arrangement were calculated along with mutation frequency, triallelic variants occurrence and MAF. 
Figure 1. Data analysis flowchart.

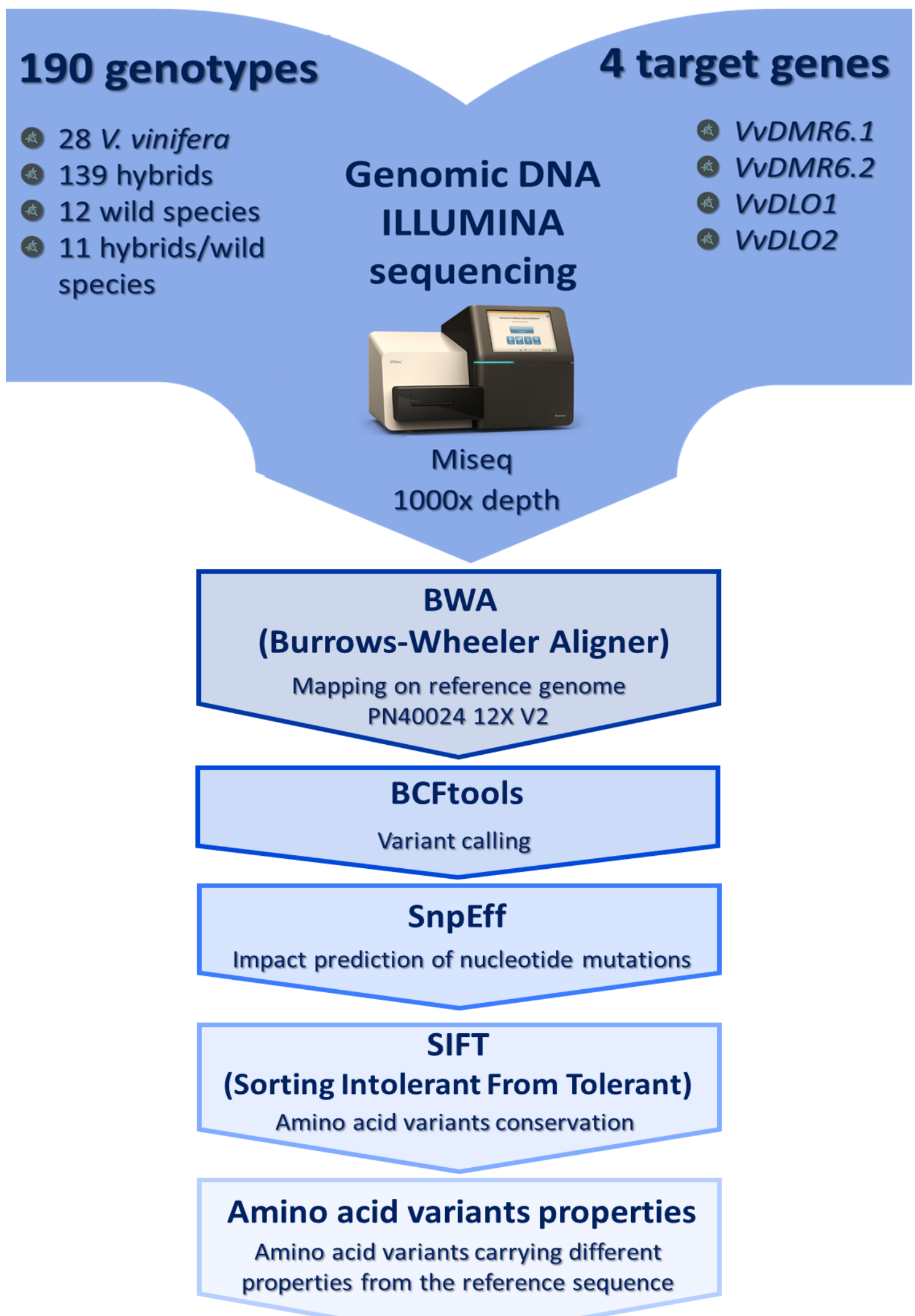

\section{MUTATIONS in 55 GENOTYPES}




\section{REFERENCES}

Aflitos, S., Schijlen, E., De Jong, H., De Ridder, D., Smit, S., Finkers, R., ... Peters, S. (2014). Exploring genetic variation in the tomato (Solanum section Lycopersicon) clade by wholegenome sequencing. Plant Journal, 80(1), 136-148. https://doi.org/10.1111/tpj.12616

Amrine, K. C. H., Blanco-Ulate, B., Riaz, S., Pap, D., Jones, L., Figueroa-Balderas, R., ... Cantu, D. (2015). Comparative transcriptomics of Central Asian Vitis vinifera accessions reveals distinct defense strategies against powdery mildew. Horticulture Research, 2(July). https://doi.org/10.1038/hortres.2015.37

Andersen, J. R., \& Lübberstedt, T. (2003). Functional markers in plants. Trends in Plant Science, 8(11), 554-560. https://doi.org/10.1016/j.tplants.2003.09.010

Arabidopsis Genome Initiative. (2000). Analysis of the genome sequence of the flowering plant Arabidopsis thaliana. Nature, 408(December), 796-815. https://doi.org/10.1038/35048692

Aranzana, M. J., Illa, E., Howad, W., \& Arús, P. (2012). A first insight into peach [Prunus persica (L.) Batsch] SNP variability. Tree Genetics and Genomes, 8(6), 1359-1369. https://doi.org/10.1007/s11295-012-0523-6

Atwell, S., Huang, Y. S., Vilhjálmsson, B. J., Willems, G., Horton, M., Li, Y., ... Nordborg, M. (2010). Genome-wide association study of 107 phenotypes in Arabidopsis thaliana inbred lines. Nature, 465(7298), 627-631. https://doi.org/10.1038/nature08800

Barba, P., Cadle-Davidson, L., Harriman, J., Glaubitz, J. C., Brooks, S., Hyma, K., \& Reisch, B. (2014). Grapevine powdery mildew resistance and susceptibility loci identified on a highresolution SNP map. Theoretical and Applied Genetics, 127(1), 73-84. https://doi.org/10.1007/s00122-013-2202-x

Bastet, A., Robaglia, C., \& Gallois, J. L. (2017). eIF4E Resistance: Natural Variation Should Guide Gene Editing. Trends in Plant Science, 22(5), 411-419. https://doi.org/10.1016/j.tplants.2017.01.008

Bastet, A., Zafirov, D., Giovinazzo, N., Guyon-Debast, A., Nogué, F., Robaglia, C., \& Gallois, J.-L. (2019). Mimicking natural polymorphism in eIF4E by CRISPR-Cas9 base editing is associated with resistance to potyviruses . Plant Biotechnology Journal, 17(9), 1736-1750. https://doi.org/10.1111/pbi.13096

Betts, M. J., \& Russel, R. B. (2003). Amino acid properties and consequences of substitutions. In Bioinformatics for Geneticists (pp. 289-316). https://doi.org/10.1002/0470867302.ch14

Bianco, L., Cestaro, A., Linsmith, G., Muranty, H., Denancé, C., Théron, A., ... Troggio, M. (2016). Development and validation of the Axiom®Apple480K SNP genotyping array. Plant 
Journal, 86(1), 62-74. https://doi.org/10.1111/tpj.13145

Bisht, D. S., Bhatia, V., \& Bhattacharya, R. (2019). Improving plant-resistance to insect-pests and pathogens: The new opportunities through targeted genome editing. Seminars in Cell and Developmental Biology, (April), 1-12. https://doi.org/10.1016/j.semcdb.2019.04.008

Biswas, C., Dey, P., Karmakar, P. G., \& Satpathy, S. (2015). Discovery of large-scale SNP markers and construction of linkage map in a RIL population of jute (Corchorus capsularis). Molecular Breeding, 35(5), 1-10. https://doi.org/10.1007/s11032-015-0311-8

Bolger, M. E., Weisshaar, B., Scholz, U., Stein, N., Usadel, B., \& Mayer, K. F. X. (2014). Plant genome sequencing - applications for crop improvement. Current Opinion in Biotechnology, 26, 31-37. https://doi.org/10.1016/j.copbio.2013.08.019

Brookes, A. J. (1999). The essence of SNPs [Review]. Gene, 234(2), 177-186. https://doi.org/10.1016/S0378-1119(99)00219-X

Burow, G., Chopra, R., Sattler, S., Burke, J., Acosta-Martinez, V., \& Xin, Z. (2019). Deployment of SNP (CAPS and KASP) markers for allelic discrimination and easy access to functional variants for brown midrib genes bmr6 and bmr12 in Sorghum bicolor. Molecular Breeding, 39(8). https://doi.org/10.1007/s11032-019-1010-7

Byers, R. L., Harker, D. B., Yourstone, S. M., Maughan, P. J., \& Udall, J. A. (2012). Development and mapping of SNP assays in allotetraploid cotton. Theoretical and Applied Genetics, 124(7), 1201-1214. https://doi.org/10.1007/s00122-011-1780-8

Campbell, N. R., Harmon, S. A., \& Narum, S. R. (2015). Genotyping-in-Thousands by sequencing (GT-seq): A cost effective SNP genotyping method based on custom amplicon sequencing. Molecular Ecology Resources, 15(4), 855-867. https://doi.org/10.1111/17550998.12357

Canaguier, A., Grimplet, J., Di Gaspero, G., Scalabrin, S., Duchêne, E., Choisne, N., ... Adam-Blondon, A. F. (2017). A new version of the grapevine reference genome assembly (12X.v2) and of its annotation (VCost.v3). Genomics Data, 14(July), 56-62. https://doi.org/10.1016/j.gdata.2017.09.002

Cardone, M. F., D’Addabbo, P., Alkan, C., Bergamini, C., Catacchio, C. R., Anaclerio, F., ... Antonacci, D. (2016). Inter-varietal structural variation in grapevine genomes. Plant Journal, 88(4), 648-661. https://doi.org/10.1111/tpj.13274

Carrier, G., Le Cunff, L., Dereeper, A., Legrand, D., Sabot, F., Bouchez, O., ... This, P. (2012). Transposable elements are a major cause of somatic polymorphism in vitis vinifera L. PLoS ONE, 7(3), 1-10. https://doi.org/10.1371/journal.pone.0032973

Cheng, L., Chen, X., Jiang, C., Ma, B., Ren, M., Cheng, Y., ... Yang, A. (2019). High-density 
SNP genetic linkage map construction and quantitative trait locus mapping for resistance to cucumber mosaic virus in tobacco (Nicotiana tabacum L.). Crop Journal, 7(4), 539-547. https://doi.org/10.1016/j.cj.2018.11.010

Ching, A., Caldwell, K. S., Jung, M., Dolan, M., Smith, O. S. H., Tingey, S., ... Rafalski, A. J. (2002). SNP frequency, haplotype structure and linkage disequilibrium in elite maize inbred lines. BMC Genetics, 3, 1-14. https://doi.org/10.1186/1471-2156-3-19

Cho, Y. B., Jones, S. I., \& Vodkin, L. O. (2017). Mutations in Argonaute5 illuminate epistatic interactions of the $\mathrm{K} 1$ and I loci leading to saddle seed color patterns in glycine max. Plant Cell, 29(4), 708-725. https://doi.org/10.1105/tpc.17.00162

Cingolani, P., Platts, A., Wang, L. L., Coon, M., Nguyen, T., Wang, L., ... Ruden, D. M. (2012). A program for annotating and predicting the effects of single nucleotide polymorphisms, SnpEff. Fly, 6(2), 80-92. https://doi.org/10.4161/fly.19695

Danecek, P., Auton, A., Abecasis, G., Albers, C. A., Banks, E., DePristo, M. A., ... Durbin, R. (2011). The variant call format and VCFtools. Bioinformatics, 27(15), 2156-2158. https://doi.org/10.1093/bioinformatics/btr330

de Toledo Thomazella, D. P., Brail, Q., Dahlbeck, D., \& Staskawicz, B. J. (2016). CRISPRCas9 mediated mutagenesis of a DMR6 ortholog in tomato confers broad-spectrum disease resistance. BioRxiv, 064824. https://doi.org/10.1101/064824

Dong, X., Wang, Z., Tian, L., Zhang, Y., Qi, D., Huo, H., ... Cao, Y. (2019). De novo assembly of a wild pear ( Pyrus betuleafolia ) genome . Plant Biotechnology Journal, 1-15. https://doi.org/10.1111/pbi.13226

Durstewitz, G., Polley, A., Plieske, J., Luerssen, H., Graner, E. M., Wieseke, R., \& Ganal, M. W. (2010). SNP discovery by amplicon sequencing and multiplex SNP genotyping in the allopolyploid species Brassica napus. Genome, 53(11), 948-956. https://doi.org/10.1139/G10079

Edwards, D., Forster, J. W., Cogan, N. O., Batley, J., \& Chagné, D. (2007). Single nucleotide polymorphism discovery. In Association mapping in plants. https://doi.org/https://doi.org/10.1007/978-0-387-36011-9_4

Emanuelli, F., Lorenzi, S., Grzeskowiak, L., Catalano, V., Stefanini, M., Troggio, M., ... Grando, M. S. (2013). Genetic diversity and population structure assessed by SSR and SNP markers in a large germplasm collection of grape. BMC Plant Biology, 13(1), 1-17. https://doi.org/10.1186/1471-2229-13-39

Fan, C., Yu, S., Wang, C., \& Xing, Y. (2009). A causal C-A mutation in the second exon of GS3 highly associated with rice grain length and validated as a functional marker. Theoretical and 
Applied Genetics, 118(3), 465-472. https://doi.org/10.1007/s00122-008-0913-1

Fawke, S., Doumane, M., \& Schornack, S. (2015). Oomycete Interactions with Plants: Infection Strategies and Resistance Principles. Microbiology and Molecular Biology Reviews, 79(3), 263-280. https://doi.org/10.1128/mmbr.00010-15

Feechan, A., Jermakow, A. M., \& Dry, I. B. (2009). Grapevine MLO candidates required for powdery mildew pathogenicity? Plant Signaling and Behavior, 4(6), 522-523. https://doi.org/10.4161/psb.4.6.8575

Feuillet, C., Leach, J. E., Rogers, J., Schnable, P. S., \& Eversole, K. (2011). Crop genome sequencing: Lessons and rationales. Trends in Plant Science, 16(2), 77-88. https://doi.org/10.1016/j.tplants.2010.10.005

ffrench-Constant, R. H., \& Bass, C. (2017). Does resistance really carry a fitness cost? Current Opinion in Insect Science, 21, 39-46. https://doi.org/10.1016/j.cois.2017.04.011

Gambino, G., Dal Molin, A., Boccacci, P., Minio, A., Chitarra, W., Avanzato, C. G., ... Delledonne, M. (2017). Whole-genome sequencing and SNV genotyping of 'Nebbiolo' (Vitis vinifera L.) clones. Scientific Reports, 7(1), 1-15. https://doi.org/10.1038/s41598-017-17405-y

Ganal, M. W., Altmann, T., \& Röder, M. S. (2009). SNP identification in crop plants. Current Opinion in Plant Biology, 12(2), 211-217. https://doi.org/10.1016/j.pbi.2008.12.009

Girollet, N., Rubio, B., \& Bert, P.-F. (2019). De novo phased assembly of the Vitis riparia grape genome. Scientific Data, 6(1), 1-8. https://doi.org/10.1038/s41597-019-0133-3

Grattapaglia, D., Silva-Junior, O. B., Kirst, M., de Lima, B. M., Faria, D. A., \& Pappas, G. J. (2011). High-throughput SNP genotyping in the highly heterozygous genome of Eucalyptus: Assay success, polymorphism and transferability across species. BMC Plant Biology, 11(1), 65. https://doi.org/10.1186/1471-2229-11-65

Gupta, P. K., Roy, J. K., \& Prasad, M. (2001). Single nucleotide polymorphisms: A new paradigm for molecular marker technology and DNA polymorphism detection with emphasis on their use in plants. Current Science, 80(4), 524-535.

Gururani, M. A., Venkatesh, J., Upadhyaya, C. P., Nookaraju, A., Pandey, S. K., \& Park, S. W. (2012). Plant disease resistance genes: Current status and future directions. Physiological and Molecular Plant Pathology, 78, 51-65. https://doi.org/10.1016/j.pmpp.2012.01.002

Hardner, C. M., Hayes, B. J., Kumar, S., Vanderzande, S., Cai, L., Piaskowski, J., ... Peace, C. P. (2019). Prediction of genetic value for sweet cherry fruit maturity among environments using a 6K SNP array. Horticulture Research, 6(1). https://doi.org/10.1038/s41438-018-00817

Hong, Y., Liao, D., Hu, A., Wang, H., Chen, J., Khan, S., ... \& Li, H. (2015). Diversity of 
endophytic and rhizoplane bacterial communities associated with exotic Spartina alterniflora and native mangrove using Illumina amplicon sequencing. Canadian Journal of Microbiology, 61(10), 723-733. https://doi.org/10.1139/cjm-2015-0079

Hulse-Kemp, A. M., Ashrafi, H., Plieske, J., Lemm, J., Stoffel, K., Hill, T., ... Van Deynze, A. (2016). A HapMap leads to a Capsicum annuum SNP infinium array: A new tool for pepper breeding. Horticulture Research, 3(June), 1-10. https://doi.org/10.1038/hortres.2016.36

Jaillon. (2007). The grapevine genome sequence suggests ancestral hexaploidization in major angiosperm phyla. Nature. https://doi.org/10.1038/nature06148

Jones, E. S., Sullivan, H., Bhattramakki, D., \& Smith, J. S. C. (2007). A comparison of simple sequence repeat and single nucleotide polymorphism marker technologies for the genotypic analysis of maize (Zea mays L.). Theoretical and Applied Genetics, 115(3), 361-371. https://doi.org/10.1007/s00122-007-0570-9

Jones, J. D. G., \& Dangl, J. L. (2006). The plant immune system. Nature, 444, 323-329. https://doi.org/10.1038/nature05286

Jorgensen, J. H. (1992). Discovery, characterization and exploitation of Mlo powdery mildew. Euphytica, 66, 141-152. https://doi.org/10.1007/BF00023919

Kinoti, W. M., Constable, F. E., Nancarrow, N., Plummer, K. M., \& Rodoni, B. (2017). Analysis of intra-host genetic diversity of Prunus necrotic ringspot virus (PNRSV) using amplicon next generation sequencing. PLoS ONE, 12(6), 1-21. https://doi.org/10.1371/journal.pone.0179284

Kumar, P., Henikoff, S., \& Ng, P. C. (2009). Predicting the effects of coding non-synonymous variants on protein function using the SIFT algorithm. Nature Protocols, 4(7), 1073-1082. https://doi.org/10.1038/nprot.2009.86

Kumar, S., Banks, T. W., \& Cloutier, S. (2012). SNP discovery through next-generation sequencing and its applications. International Journal of Plant Genomics, 2012. https://doi.org/10.1155/2012/831460

Kusch, S., \& Panstruga, R. (2017). mlo-Based Resistance: An Apparently Universal 'Weapon' to Defeat Powdery Mildew Disease. Molecular Plant-Microbe Interactions : MPMI, 30(3), 179189. https://doi.org/10.1094/MPMI-12-16-0255-CR

Li, H., Handsaker, B., Wysoker, A., Fennell, T., Ruan, J., Homer, N., ... Durbin, R. (2009). The Sequence Alignment/Map format and SAMtools. Bioinformatics, 25(16), 2078-2079. https://doi.org/10.1093/bioinformatics/btp352

Li, Heng, \& Durbin, R. (2010). Fast and accurate long-read alignment with Burrows-Wheeler transform. Bioinformatics, 26(5), 589-595. https://doi.org/10.1093/bioinformatics/btp698 
Li, X., Singh, J., Qin, M., Li, S., Zhang, X., Zhang, M., ... Wu, J. (2019). Development of an integrated 200K SNP genotyping array and application for genetic mapping, genome assembly improvement and genome wide association studies in pear ( Pyrus ). Plant Biotechnology Journal, 17(8), 1582-1594. https://doi.org/10.1111/pbi.13085

Lijavetzky, D., Cabezas, J., Ibáñez, A., Rodríguez, V., \& Martínez-Zapater, J. M. (2007). High throughput SNP discovery and genotyping in grapevine (Vitis vinifera L.) by combining a resequencing approach and SNPlex technology. BMC Genomics, 8, 1-11. https://doi.org/10.1186/1471-2164-8-424

Marrano, A., Birolo, G., Prazzoli, M. L., Lorenzi, S., Valle, G., \& Grando, M. S. (2017). SNPdiscovery by RAD-sequencing in a germplasm collection of wild and cultivated grapevines (V. vinifera L.). PLoS ONE, 12(1), 1-19. https://doi.org/10.1371/journal.pone.0170655

Marrano, A., Martínez-García, P. J., Bianco, L., Sideli, G. M., Di Pierro, E. A., Leslie, C. A., ... Neale, D. B. (2019). A new genomic tool for walnut (Juglans regia L.): development and validation of the high-density Axiom ${ }^{\mathrm{TM}} \mathrm{J}$. regia 700K SNP genotyping array. Plant Biotechnology Journal, 17(6), 1027-1036. https://doi.org/10.1111/pbi.13034

Merot-L'anthoene, V., Tournebize, R., Darracq, O., Rattina, V., Lepelley, M., Bellanger, L., ... Poncet, V. (2019). Development and evaluation of a genome-wide Coffee 8.5K SNP array and its application for high-density genetic mapping and for investigating the origin of Coffea arabica L. Plant Biotechnology Journal, 17(7), 1418-1430. https://doi.org/10.1111/pbi.13066

Meyers, B. C., Kaushik, S., \& Nandety, R. S. (2005). Evolving disease resistance genes. Current Opinion in Plant Biology, 8(2), 129-134. https://doi.org/10.1016/j.pbi.2005.01.002

Owens, C. L. (2003). SNP detection and genotyping in Vitis. Acta Horticulturae, 603, 139-140. https://doi.org/10.17660/ActaHortic.2003.603.17

Pessina, S., Lenzi, L., Perazzolli, M., Campa, M., Dalla Costa, L., Urso, S., ... Malnoy, M. (2016). Knockdown of MLO genes reduces susceptibility to powdery mildew in grapevine. Horticulture Research, 3(November 2015). https://doi.org/10.1038/hortres.2016.16

Peterson, G. W., Dong, Y., Horbach, C., \& Fu, Y. B. (2014). Genotyping-by-sequencing for plant genetic diversity analysis: A lab guide for SNP genotyping. Diversity, 6(4), 665-680. https://doi.org/10.3390/d6040665

Polanco, C., Sáenz de Miera, L. E., González, A. I., García, P., Fratini, R., Vaquero, F., ... De La Vega, M. P. (2019). Construction of a high-density interspecific (Lens culinaris x L. Odemensis) genetic map based on functional markers for mapping morphological and agronomical traits, and QTLs affecting resistance to Ascochyta in lentil. PLoS ONE, 14(3), 121. https://doi.org/10.1371/journal.pone.0214409 
Raman, H., Dalton-Morgan, J., Diffey, S., Raman, R., Alamery, S., Edwards, D., \& Batley, J. (2014). SNP markers-based map construction and genome-wide linkage analysis in Brassica napus. Plant Biotechnology Journal, 12(7), 851-860. https://doi.org/10.1111/pbi.12186

Roach, M. J., Johnson, D. L., Bohlmann, J., van Vuuren, H. J. J., Jones, S. J. M., Pretorius, I. S., ... Borneman, A. R. (2018). Population sequencing reveals clonal diversity and ancestral inbreeding in the grapevine cultivar Chardonnay. PLoS Genetics, 14(11). https://doi.org/10.1371/journal.pgen.1007807

Rodríguez-Leal, D., Lemmon, Z. H., Man, J., Bartlett, M. E., \& Lippman, Z. B. (2017). Engineering Quantitative Trait Variation for Crop Improvement by Genome Editing. Cell, 171(2), 470-480.e8. https://doi.org/10.1016/j.cell.2017.08.030

Salmaso, M., Faes, G., Segala, C., Stefanini, M., Salakhutdinov, I., Zyprian, E., ... Velasco, R. (2004). Genome diversity and gene haplotypes in the grapevine (Vitis. Molecular Breeding, 385-395. https://doi.org/10.1016/j.neuroscience.2011.02.004

Salmaso, M., Malacarne, G., Troggio, M., Faes, G., Stefanini, M., Grando, M. S., \& Velasco, R. (2008). A grapevine (Vitis vinifera L.) genetic map integrating the position of 139 expressed genes. Theoretical and Applied Genetics, 116(8), 1129-1143. https://doi.org/10.1007/s00122-008-0741-3

Schaart, J. G., van de Wiel, C. C. M., Lotz, L. A. P., \& Smulders, M. J. M. (2016). Opportunities for Products of New Plant Breeding Techniques. Trends in Plant Science, 21(5), 438-449. https://doi.org/10.1016/j.tplants.2015.11.006

Schadt, E. E., Turner, S., \& Kasarskis, A. (2010). A window into third-generation sequencing. Human Molecular Genetics, 19(R2), 227-240. https://doi.org/10.1093/hmg/ddq416

Schneider, K., Weisshaar, B., Borchardt, D. C., \& Salamini, F. (2001). SNP frequency and allelic haplotype structure of Beta vulgaris expressed genes. Molecular Breeding, 8(1), 63-74. https://doi.org/10.1023/A:1011902916194

Schouten, H. J., Krauskopf, J., Visser, R. G. F., \& Bai, Y. (2014). Identification of candidate genes required for susceptibility to powdery or downy mildew in cucumber. Euphytica, 200(3), 475-486. https://doi.org/10.1007/s10681-014-1216-Z

Shimray, P. W., Bajaj, D., Srivastava, R., Daware, A., Upadhyaya, H. D., Kumar, R., ... Parida, S. K. (2017). Identifying Transcription Factor Genes Associated with Yield Traits in Chickpea. Plant Molecular Biology Reporter, 35(5), 562-574. https://doi.org/10.1007/s11105017-1044-0

Simko, I., Haynes, K. G., \& Jones, R. W. (2006). Assessment of linkage disequilibrium in potato genome with single nucleotide polymorphism markers. Genetics, 173(4), 2237-2245. 
https://doi.org/10.1534/genetics.106.060905

Sun, K., van Tuinen, A., van Kan, J. A. L., Wolters, A. M. A., Jacobsen, E., Visser, R. G. F., \& Bai, Y. (2017). Silencing of DND1 in potato and tomato impedes conidial germination, attachment and hyphal growth of Botrytis cinerea. BMC Plant Biology, 17(1), 235. https://doi.org/10.1186/s12870-017-1184-2

Thavamanikumar, S., McManus, L. J., Tibbits, J. F. G., \& Bossinger, G. (2011). The significance of single nucleotide polymorphisms (SNPs) in Eucalyptus globulus breeding programs. Australian Forestry, 74(1), 23-29. https://doi.org/10.1080/00049158.2011.10676342

Topfer.R Hausmann L., 2010. (2010). Table of Loci for Traits in Grapevine Relevant for Breeding and Genetics. 40024(2011), 2011-2014. Retrieved from http://www.genoscope.cns.fr/vitis\%0Ahttp://www.vivc.de/docs/dataonbreeding/20180122_Ta ble of Loci for Traits in Grapevine.pdf

Tuskan, G. A., Difazio, S., Jansson, S., Bohlmann, J., Grigoriev, I., Hellsten, U., ... \& Schein, J. (2006). The Genome of Black Cottonwood Populus trichocarpa (Torr. \& Gray). Science, 313(September), 1596-1604. https://doi.org/10.1126/science.1128691

\section{Van Damme, M., Andel, A., Huibers, R. P., Panstruga, R., Weisbeek, P. J., \& Van Den} Ackerveken, G. (2005). Identification of Arabidopsis loci required for susceptibility to the downy mildew pathogen Hyaloperonospora parasitica. Molecular Plant-Microbe Interactions, 18(6), 583-592. https://doi.org/10.1094/MPMI-18-0583

Van Damme, M., Huibers, R. P., Elberse, J., \& Van Den Ackerveken, G. (2008). Arabidopsis DMR6 encodes a putative 2OG-Fe(II) oxygenase that is defense-associated but required for susceptibility to downy mildew. Plant Journal, 54(5), 785-793. https://doi.org/10.1111/j.1365313X.2008.03427.X

van Schie, C. C. N., \& Takken, F. L. W. (2014). Susceptibility Genes 101: How to Be a Good Host. Annual Review of Phytopathology, 52(1), 551-581. https://doi.org/10.1146/annurevphyto-102313-045854

Varshney, R. K., Nayak, S. N., May, G. D., \& Jackson, S. A. (2009). Next-generation sequencing technologies and their implications for crop genetics and breeding. Trends in Biotechnology, 27(9), 522-530. https://doi.org/10.1016/j.tibtech.2009.05.006

Velasco, R., Zharkikh, A., Troggio, M., Cartwright, D. A., Cestaro, A., Pruss, D., ... Viola, R. (2007). A High Quality Draft Consensus Sequence of the Genome of a Heterozygous Grapevine Variety. PLoS ONE, 2(12), e1326. https://doi.org/10.1371/journal.pone.0001326 Vezzulli, S., Micheletti, D., Riaz, S., Pindo, M., Viola, R., This, P., ... Velasco, R. (2008a). A 
SNP transferability survey within the genus Vitis. BMC Plant Biology, 8, 1-10. https://doi.org/10.1186/1471-2229-8-128

Vezzulli, S., Troggio, M., Coppola, G., Jermakow, A., Cartwright, D., Zharkikh, A., ...

Velasco, R. (2008b). A reference integrated map for cultivated grapevine (Vitis vinifera L.) from three crosses, based on 283 SSR and 501 SNP-based markers. Theoretical and Applied Genetics, 117(4), 499-511. https://doi.org/10.1007/s00122-008-0794-3

Vitulo, N., Forcato, C., Carpinelli, E., Telatin, A., Campagna, D., D’Angelo, M., ... Valle, G. (2014). A deep survey of alternative splicing in grape reveals changes in the splicing machinery related to tissue, stress condition and genotype. BMC Plant Biology, 14(1), 99. https://doi.org/10.1186/1471-2229-14-99

Vos, P. G., Uitdewilligen, J. G. A. M. L., Voorrips, R. E., Visser, R. G. F., \& van Eck, H. J. (2015). Development and analysis of a 20K SNP array for potato (Solanum tuberosum): an insight into the breeding history. Theoretical and Applied Genetics, 128(12), 2387-2401. https://doi.org/10.1007/s00122-015-2593-y

Winterhagen, P., Howard, S. F., Qiu, W., \& Kovács, L. G. (2008). Transcriptional up-regulation of grapevine MLO genes in response to powdery mildew infection. American Journal of Enology and Viticulture, 59(2), 159-168. Retrieved from https://www.ajevonline.org/content/59/2/159.long

Wolter, F., \& Puchta, H. (2018). Application of CRISPR/Cas to Understand Cis- and TransRegulatory Elements in Plants. In Methods in Molecular Biology (pp. 23-40). https://doi.org/10.1007/978-1-4939-8657-6_2

Wu, S. B., Wirthensohn, M. G., Hunt, P., Gibson, J. P., \& Sedgley, M. (2008). High resolution melting analysis of almond SNPs derived from ESTs. Theoretical and Applied Genetics, 118(1), 1-14. https://doi.org/10.1007/s00122-008-0870-8

Xanthopoulou, A., Montero-Pau, J., Mellidou, I., Kissoudis, C., Blanca, J., Picó, B., ... Ganopoulos, I. (2019). Whole-genome resequencing of Cucurbita pepo morphotypes to discover genomic variants associated with morphology and horticulturally valuable traits. Horticulture Research, 6(1). https://doi.org/10.1038/s41438-019-0176-9

Xu, X., Liu, X., Ge, S., Jensen, J. D., Hu, F., Li, X., ... Wang, W. (2012). Resequencing 50 accessions of cultivated and wild rice yields markers for identifying agronomically important genes. Nature Biotechnology, 30(1), 105-111. https://doi.org/10.1038/nbt.2050

Yang, S., Fresnedo-Ramírez, J., Wang, M., Cote, L., Schweitzer, P., Barba, P., ... Sun, Q. (2016). A next-generation marker genotyping platform (AmpSeq) in heterozygous crops: A case study for marker-assisted selection in grapevine. Horticulture Research, 3(December 
2015). https://doi.org/10.1038/hortres.2016.2

Yang, Y., Zhang, H., Xuan, N., Chen, G., Liu, X., Yao, F., \& Ding, H. (2017). Identification of blast resistance genes in 358 rice germplasms (Oryza sativa L.) using functional molecular markers. European Journal of Plant Pathology, 148(3), 567-576. https://doi.org/10.1007/s10658-016-1112-6

Zaidi, S. S. e. A., Mukhtar, M. S., \& Mansoor, S. (2018). Genome Editing: Targeting Susceptibility Genes for Plant Disease Resistance. Trends in Biotechnology, 36(9), 898-906. https://doi.org/10.1016/j.tibtech.2018.04.005

Zeilmaker, T., Ludwig, N. R., Elberse, J., Seidl, M. F., Berke, L., Van Doorn, A., ... Van Den Ackerveken, G. (2015). Downy mildew resistant 6 and DMR6-like oxygenase 1 are partially redundant but distinct suppressors of immunity in Arabidopsis. Plant Journal, 81(2), 210-222. https://doi.org/10.1111/tpj.12719

Zhang, S., Shi, Q., Duan, Y., Hall, D., Gupta, G., \& Stover, E. (2018). Regulation of citrus DMR6 via RNA interference and CRISPR/Cas9-mediated gene editing to improve Huanglongbing tolerance. In PHYTOPATHOLOGY (Vol. 108, p. 13).

Zhang, K., Halitschke, R., Yin, C., Liu, C.-J., \& Gan, S.-S. (2013). Salicylic acid 3-hydroxylase regulates Arabidopsis leaf longevity by mediating salicylic acid catabolism. Proceedings of the National Academy of Sciences, 110(36), 14807-14812. https://doi.org/10.1073/pnas.1302702110

Zhang, W., Mirlohi, S., Li, X., \& He, Y. (2018). Identification of functional single-nucleotide polymorphisms affecting leaf hair number in Brassica rapa. Plant Physiology, 177(2), 490503. https://doi.org/10.1104/pp.18.00025

Zhang, Y. J., Zhao, L., Zhao, J. Z., Li, Y. J., Wang, J. Bin, Guo, R., ... Zhanga, K. W. (2017). S5H/DMR6 encodes a salicylic acid 5-hydroxylase that fine-tunes salicylic acid homeostasis. Plant Physiology, 175(3), 1082-1093. https://doi.org/10.1104/pp.17.00695

Zhu, Y. L., Song, Q. J., Hyten, D. L., Van Tassell, C. P., Matukumalli, L. K., Grimm, D. R., ... Cregan, P. B. (2003). Single-nucleotide polymorphisms in soybean. Genetics, 163(3), 11231134. Retrieved from https://www.genetics.org/content/163/3/1123.short 